\title{
PROMOSI KESEHATAN MASYARAKAT PIJAT AMAN, BAYI SENANG DI POSDAYA ANGGREK HUSADA KELURAHAN KEDUNGMUNDU KECAMATAN TEMBALANG KOTA SEMARANG
}

\author{
Sri Mulyati*) ; Darmini Darmini ; Jeffri Ardiyanto; Gatot Murti Wibowo \\ Jurusan Teknik Radiodiagnostik dan Radioterapi ; Poltekkes Kemenkes Semarang \\ Jl. Tirto Agung ; Pedalangan ; Banyumanik; Semarang
}

\begin{abstract}
Abstrak
Pijat bayi dapat diartikan sebagai sentuhan komunikasi yang nyaman antara ibu dan bayi. Pijat bayi merupakan ungkapan rasa kasih sayang antara orang tua dengan anak lewat sentuhan pada kulit. Stimulasi merupakan hal yang penting dalam tumbuh kembang anak. Anak yang mendapat stimulasi yang terarah dan teratur akan lebih cepat berkembang dibandingkan dengan anak yang kurang atau tidak mendapat stimulasi. Sentuhan ibu juga akan direspon oleh bayi sebagai bentuk perlindungan, perhatian, dan ungkapan cinta. Tujuan dan manfaat pijat bayi sangat banyak, bagi bayi sendiri maupun ibu antara lain bermanfaat untuk meningkatkan kepercayaan diri, memudahkan orang tua mengenali bayinya, membina ikatan kasih sayang orang tua dan anak (bounding). Metode pengabdian dilakukan dengan cara ceramah dan simulasi pijat bayi. Promosi kesehatan dilakukan oleh dosen dan mahasiswa Jurusan Teknik Radiodiagnostik dan Radioterapi. Kegiatan bertempat di Balai Pertemuan Perum Sinar Waluyo RT 11 RW 01 Kelurahan Kedungmundu dengan tema "Pijat Aman, Bayi Senang". Pelaksanaannya pada saat kegiatan posyandu dan didukung narasumber dari Rumah Sakit Roemani Muhammadiyah Semarang. Peserta kegiatan sekitar 50 orang ibu dan bayi. Kegiatan dapat berjalan lancar, antusiasme warga dan respon yang positif. Diharapkan program tersebut dapat dilanjutkan di masa mendatang dengan topik yang berbeda sebagai wujud pengabdian masyarakat.
\end{abstract}

Kata kunci: Pijat Bayi ; Ceramah promosi kesehatan ; Simulasi

\begin{abstract}
[PROMOTION OF PUBLIC HEALTH SAFE MASSAGE, HAPPY BABY IN POSDAYA ANGGREK HUSADA WARDS KEDUNGMUNDU DISTRICT TEMBALANG SEMARANG] Infant massage can be interpreted as a touch of a convenient communication between mother and baby. Infant massage is an expression of love between parents and baby through contact with skin. Stimulation is important in child development. Children who get stimulation targeted and will regularly grow faster than children who are less or not stimulated. Mother's touch will also be addressed by the baby as a form of protection, attention, and expressions of love and benefits of infant massage are numerous, both for themselves and the baby's mother, among other things useful to boost confidence, facilitate parents to know baby, build a bond of love the parents and children (bounding). Methods dedication done by lectures and simulated infant massage. Health promotion is done by the lecturers and students of Department of radiodiagnostic and radiotherapy. Activities located in Hall Meeting Sinar Waluyo Housing Complex RT 11 RW 01, Kedungmundu Village. Its implementation is equivalent to posyandu activities and sources of support Roemani Muhammadiyah Hospital Semarang. Participants of about 50 mothers and babies. Activities will run succesfully, and the enthusiasm of a positive response. It is expected that the program can continue in the future as a community service.
\end{abstract}

Keywords: Baby massage ; Health promotion lecture ; Simulation

\section{Pendahuluan}

Pijat bayi biasa disebut dengan stimulus touch. Pijat bayi dapat diartikan sebagai

\footnotetext{
*) Sri Mulyati
}

E-mail: cici.mulyadi@gmail.com sentuhan komunikasi yang nyaman antara ibu dan bayi. Pijat bayi sudah dikenal sejak berabad-abad yang lalu, pada berbagai bangsa dan kebudayaan, dengan berbagai bentuk terapi dan tujuan. Pijat bayi merupakan pengungkapan rasa kasih sayang antara orang tua dengan anak 
lewat sentuhan pada kulit yang berdampak sangat luar biasa. Sentuhan dan pelukan adalah salah satu kebutuhan dasar bayi.

Stimulasi merupakan hal yang penting dalam tumbuh kembang anak. Anak yang mendapat stimulasi yang terarah dan teratur akan lebih cepat berkembang dibandingkan dengan anak yang kurang atau tidak mendapat stimulasi.

Sentuhan ibu juga akan direspon oleh bayi sebagai bentuk perlindungan, perhatian, dan ungkapan cinta. Semakin padat frekuensi sentuhan, semakin dekat hubungan batin yang terjalin. Oleh sebab itu, pemijatan sebaiknya dilakukan oleh ayah, kakek atau nenek agar bayi tidak semakin tinggi ketergantungannya hanya terhadap ibu.

a. Tujuan Pijat Bayi

1) Mencegah posisi yang salah

2) Mencegah terjadinya kontraktur

3) Memperbaiki tonus otot

4) Meningkatkan visual dan auditory reaction

5) Pendidikan orang tua dalam cara menggendong dan memandikan bayi

b. Manfaat Pijat Bayi

1) Manfaat bagi bayi
a) Meningkatkan berat badan
b) Membuat bayi semakin tenang
c) Meningkatkan efektivitas istirahat (tidur bayi)
d) Meningkatkan pertumbuhan
e) Memperbaiki konsentrasi bayi
f) Meningkatkan produksi ASI
g) Membantu meringankan ketidaknyamanan dalam pencernaan dan tekanan emosi
h) Memacu perkembangan otak dan sistim saraf
i) Meningkatkan gerak peristaltik untuk pencernaan
j) Menstimulasi aktivitas Nervus Vagus untuk perbaikan pernafasan
k) Memperkuat sistim kekebalan tubuh
1) Mengajari bayi sejak dini tentang bagian tubuh
m) Meningkatkan aliran oksigen dan nutrisi menuju sel

\section{2) Manfaat bagi ibu}

a) Meningkatkan kepercayaan diri
b) Memudahkan orang tua mengenali bayinya

c) Membina ikatan kasih sayang
orang tua dan anak (bounding)

\section{Metode}

Dalam kegiatan promosi kesehatan dengan tema pijat bayi dan moto pijat aman, bayi senang ini dilakukan oleh tim pengabdian kepada masyarakat dari dosen dan mahasiswa Jurusan Teknik Radiodiagnostik dan Radioterapi Semarang. Narasumber kegiatan dari RS Roemani Muhammadiyah. Metode yang digunakan adalah metode ceramah dan dilanjutkan simulasi praktek dengan menggunakan panthom manekin bayi. Dengan metode tersebut diharapkan ibu dan balita dapat memahami, tujuan, manfaat dan mengetahui prosedur atau cara memijat bayi yang aman dan benar dari ahlinya. Pijat bayi ini dilakukan dari kaki, perut, dada, tangan, muka, punggung dan diakhiri dengan gerakan relaksasi.

\section{Hasil dan Pembahasan}

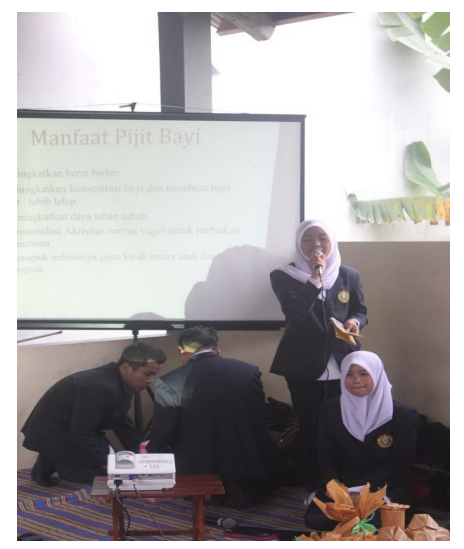

Gambar 1. Penyampaian materi pijat bayi oleh mahasiswa Jurusan Teknik Radiodiagnostik dan Radioterapi

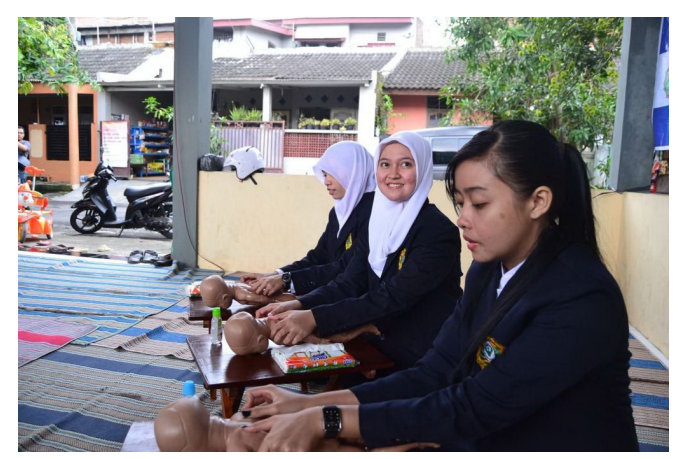

Gambar 2. Simulasi Pijat Bayi oleh Mahasiswa Jurusan Teknik Radiodiagnostik dan Radioterapi Semarang 
Promosi kesehatan dilakukan oleh kelompok dosen dan mahasiswa Jurusan Teknik Radiodiagnostik dan Radioterapi. Kegiatan bertempat di Balai Pertemuan Perumahan Sinar Waluyo RT 11 RW 01 Kelurahan Kedungmundu Tembalang Semarang dengan tema "Pijat Aman, Bayi Senang".

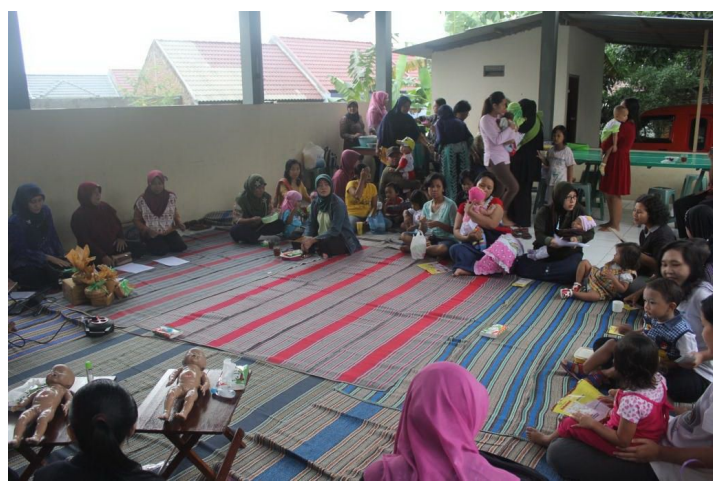

Gambar 3. Antusiasme warga mengikuti acara kegiatan promosi kesehatan masyarakat "Pijat Aman, Bayi Senang"

Waktu pelaksanaan kegiatan dilakukan bersamaan pada saat kegiatan posyandu dengan mendatangkan narasumber dari Rumah Sakit Roemani Muhammadiyah Semarang. Kegiatan dimulai dengan penyampaian materi dari nara sumber, setelah itu dilanjutkan simulasi pijat bayi dan dilanjutkan sesi tanya jawab. Selain itu, masyarakat juga terlibat aktif, sehingga meminta narasumber mensimulasikan pijat bayi pada bayi yang sesungguhnya. Dengan serta merta salah satu peserta menyerahkan bayinya untuk praktek simulasi pijat bayi agar lebih jelas dan paham tata cara pijat bayi yang aman dan benar. Sehingga, nantinya mereka akan lebih paham dan bisa mempraktekkan secara mandiri.

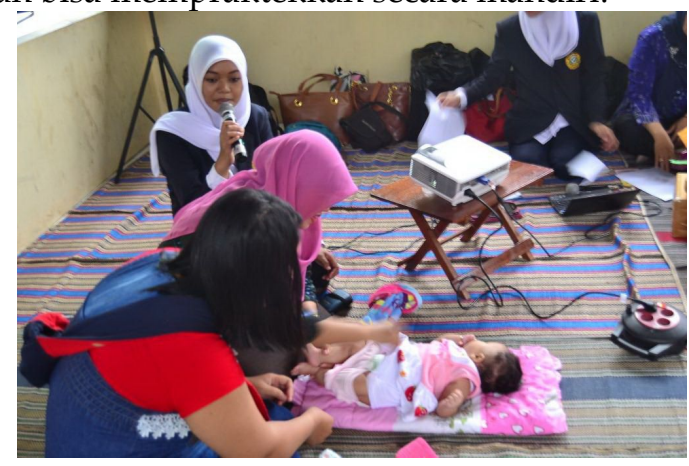

Gambar 4. Simulasi pijat bayi oleh narasumber dari RS Roemani Muhammadiyah Semarang dengan bayi sesungguhnya

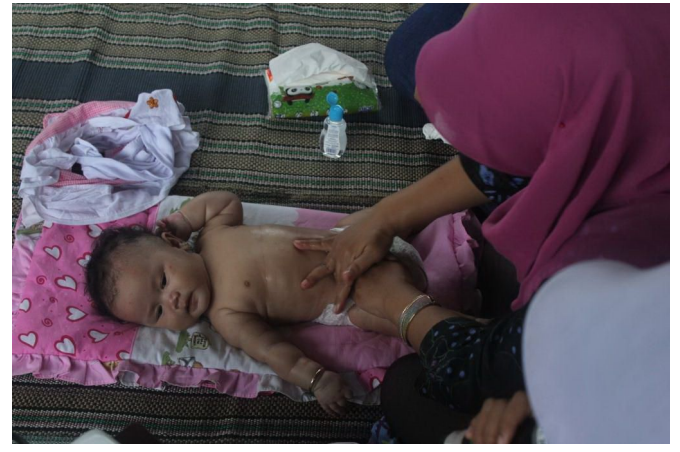

Gambar 5. Simulasi prosedur pijat bayi oleh nara sumber dari RS Roemani Muhammadiyah Semarang

Kegiatan ini dihadiri oleh sekitar 50 orang ibu dan bayi. Antusiasme warga terlihat pada saat kegiatan berlangsung dan tanggapan positif dari feed back yang diberikan oleh warga terhadap kegiatan ini. Harapan masyarakat kegiatan seperti ini dapat dilanjutkan di masa mendatang dengan topik yang berbeda.

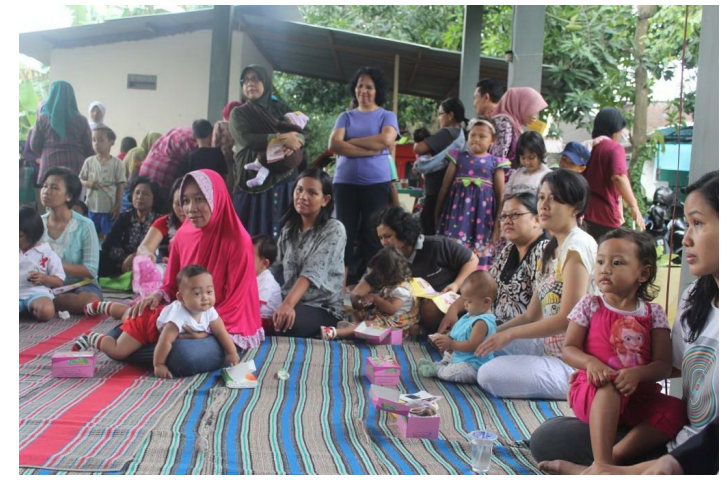

Gambar 6. Peserta mengikuti dan memperhatikan simulasi pijat bayi oleh narasumber

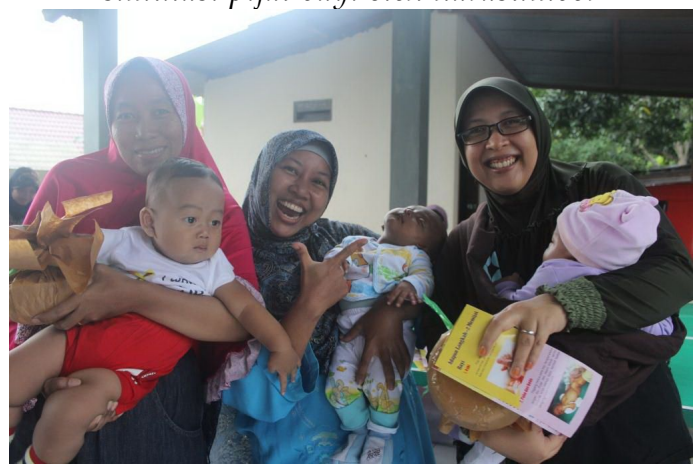

Gambar 7. Peserta mengikuti promosi kesehatan masyarakat Pijat Bayi dengan topik" Pijat Aman,

Bayi Senang" dengan antusias dan gembira

\section{Simpulan dan Saran}

Kegiatan ini dapat berlangsung baik dan 
lancar dan mendapatkan respon yang positif dari masyarakat. Diharapkan kegiatan serupa dapat berlanjut di masa mendatang dengan topik yang berbeda. Dengan kegiatan ini, masyarakat menjadi mengetahui tujuan dan manfaat pijat bayi serta dapat mengaplikasikan pijat bayi pada balita mereka sehingga bayi/balita mereka akan tumbuh dan berkembang secara baik dan meningkatkan bounding antara ibu dan bayi.

Saran masyarakat menyambut baik kegiatan semacam ini perlu ditindaklanjuti melalui program yang berkesinambungan agar manfaat lebih dapat dirasakan oleh masyarakat binaan ataupun khalayak umum lainnya sebagai wujud kontribusi Perguruan Tinggi dalam Pengabdian kepada Masyarakat di wilayah Kedungmundu.

\section{Ucapan Terima Kasih}

Terima kasih kami haturkan kepada Direktur Poltekkes Kemenkes Semarang; Ka UPPM Poltekkes Kemenkes Semarang; Ketua Jurusan Teknik Radiodiagnostik dan Radioterapi Semarang; Dan semua pihak yang terlibat secara aktif dalam kegiatan pengabdian kepada masyarakat ini.

\section{Daftar Pustaka}

Brainbridge, N \& Health, (2001) A. Baby Massage (Kekuatan Menenangkan Dari Sentuhan). Jakarta : Dain Rakyat.

Dewi, S. (2005) Pijat dan Asupan Gizi Tepat untuk Melejitkan Tumbuh Kembang Anak.

Yogyakarta : Pustaka Baru Press.

Putri, A. (2009) Pijat dan Senam untuk Bayi dan Balita Panduan Praktis Memijat Bayi dan Balita. Yogyakarta : Briliant Offset.

Roesli, U. (2001) Pedoman Pijat bayi. Jakarta : Edisi Revisi, Agriwidya.

Roesli, U. (2004) Pedoman Pijat Bayi. Jakarta : Trubus Agriwidya, Anggota IKAPI, MBA, CIMI, dan Jhonson and Jhonson.

Rosalina, I. (2007) Fisiologi Pijat Bayi. Bandung : Trikarsa Multri Media dan Jhonson and Jhoson Indonesia.

Soedjatmiko. (2006) Pedoman Praktis Pemijatan Bayi. Tangerang : Karisma Publishing Group.

Subakti, Yazid \& Deri R. (2008) Keajaiban Pijat Bayi \& Balita. Jakarta : Wahyu Media.

Suririnah. (2009), Buku Pintar Merawat Bayi 0-12 bulan. Jakarta : Gramedia Pustaka Utama.
Zulfa Hersis P, Pengaruh pijat terhadap lama tidur bayi usia 3-6 bulan di Rumah Sakit Keluarga Sehat Pati http://www.digilib.unimus.ac.id/ 